\title{
Quantitative risk assessment of engineering slag asphalt mixes for urban highways
}

\author{
Shtephan Yuriy Vitalievich \\ Moscow Automobile and Road Construction State \\ Technical University \\ Moscow, Russia \\ shtephan_y_v@mail.ru
}

\author{
Bondarev Boris Aleksandrovich \\ Lipetsk State Technical University, \\ "LipetskNICstrojproject" Ltd \\ Lipetsk, Russia \\ lnsp-48@mail.ru
}

\begin{abstract}
The results of a quantitative risk assessment for engineering stone mastic asphalts on blast-furnace slag aggregates are presented in this paper. The MathCad software module has been used. It has been shown that managing the properties of asphalt concretes significantly reduces the risk of defects appearing on road surfaces that contribute to the occurrence of road accidents. The research results have been used during the repairs of city road surfaces in Lipetsk
\end{abstract}

Keywords-stone mastic asphalt, cast slag crushed stone, technical risks assessment, roughness index IRI

\section{INTRODUCTION}

Nowadays considerable attention has recently been paid to the assessment of technical risks in the selection of asphalt concrete mixes [1]. Such assessment allows taking into account possible risks of occurrence of danger defects on road surfaces, especially if there are slopes and increased traffic intensity in city streets. Our review article in a newspaper, the Russian Road Worker, which mentioned the work of State Technical University - MADI (STU-MADI), to create an expert system for risk assessment as an alternative to confirming the compliance of industry products with the requirement of technical regulations at all stages of the road life cycle and its facilities [2], and a vigorous discussion in the scientific community has encouraged to publish this paper with some results and arguments.

A study of improving road safety by taking into account the international roughness index (IRI) and the complex index of a transport-operational condition of road surfaces is presented by Russian scientists [3]. The effect of decreasing the number of car accidents on highway sections with the increased index of a transport-operational condition has been estimated by 50 per cent based on using an econometric model with qualitative natural factors and taking into account the information of the Automated Road Data Bank (ARDB) "Road" [11]. The authors' researches have shown that decreasing the IRI index can reduce the risk of accidents to $40 \%$ for multi-lane roads and up to $17 \%$ for two-lane ones depending on the initial values of the evenness index.

Research results have allowed making a conclusion about the significant influence of the evenness of highway surfaces on road safety. As a result, it has been found out that the dependence of the risk indicator on certain types of damage on the road surface and the accident dependence on the index of longitudinal road evenness for various highways have a statistical relationship. The nature of this relationship is explained by the driver's perceiving the damage of the roadway covering and choosing the driver's behavior patterns.

Similar data are also presented by the researchers [4] on the use of the index of the level of asphalt-concrete coatings in accordance with the requirements of National Standard of the Russian Federation (GOST R 56925-2016) [5] for the countries of the Eurasian Economic Community customs union (EurAsEC) (refer with: Fig. 1)

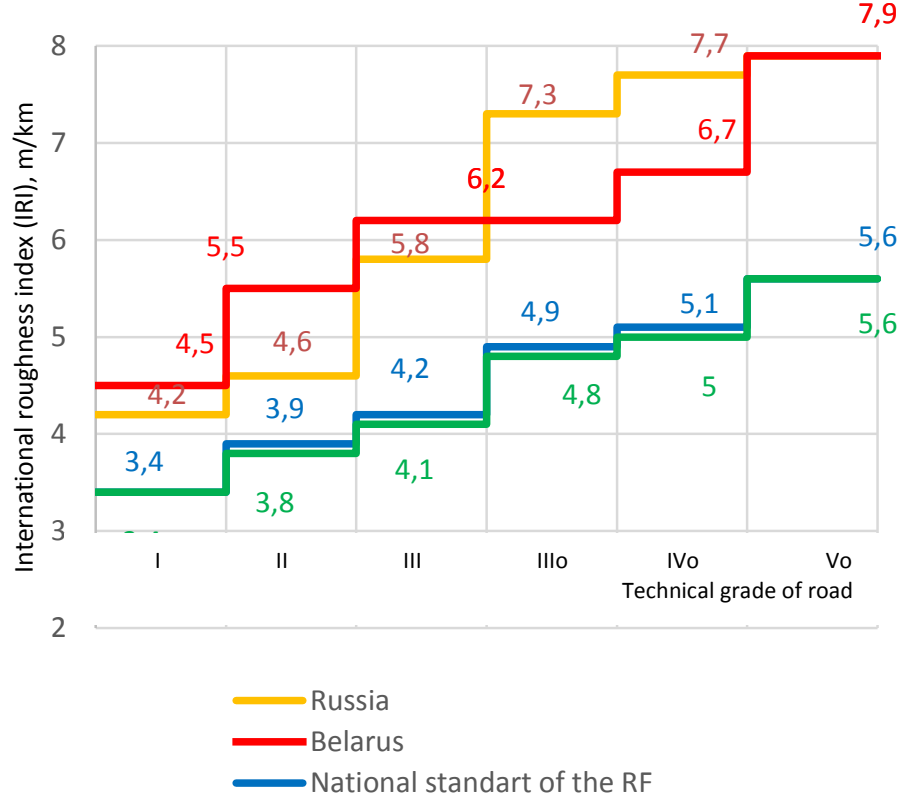

Fig. 1. The monitoring results of city road surfaces in Lipetsk. The coating proportion having regulatory properties. (Row 1 (blue) - areas with normative coupling properties of the coating, Row 2 (red) - areas with a standard evenness)

\section{RESEARCH RESULTS}

Studying of slag asphalt concretes with activated powder has been carried out in the present work. The results of these tests are summarized in Table 1.

Comparing these tests results of asphalt concretes with the requirements of the Russian National Standard on SMA, it can be established that they are within the limits of the normative strength indicators for this type of asphalt concretes. A similar conclusion can be drawn about the temperature properties: 
fracture strength as an ultimate tensile strength at a temperature of $0^{\circ} \mathrm{C}$ and shearing adhesion at a temperature of $50^{0} \mathrm{C}$.

TABLE 1. CHARACTERISTICS OF SMA ON BLAST-FURNACE SLAG AGGREGATES.

\begin{tabular}{|c|c|c|c|c|}
\hline \multirow{2}{*}{$\begin{array}{c}\text { Experiment } \\
\text { No. }\end{array}$} & \multicolumn{4}{|c|}{ Properties } \\
\cline { 2 - 5 } & $\begin{array}{c}\text { Compressive } \\
\text { strength at } \\
\mathbf{2 0} \mathbf{C}, \boldsymbol{\text { MPa }}\}\end{array}$ & $\begin{array}{c}\text { Fracture } \\
\text { strength, } \\
\text { \{MPa }\}\end{array}$ & $\begin{array}{c}\text { Coefficient of } \\
\text { internal } \\
\text { friction }\end{array}$ & $\begin{array}{c}\text { Shearing } \\
\text { adhesion } \\
\text { at 50. C }\end{array}$ \\
\hline 1 & 3.59 & 3.08 & 0.93 & 0.27 \\
\hline 2 & 3.14 & 3.47 & 0.95 & 0.26 \\
\hline 3 & 3.66 & 3.05 & 0.92 & 0.27 \\
\hline 4 & 4.03 & 3.13 & 0.94 & 0.23 \\
\hline 5 & 3.88 & 3.22 & 0.97 & 0.27 \\
\hline 6 & 3.72 & 3.11 & 0.91 & 0.25 \\
\hline Av. & 3.67 & 3.18 & 9.94 & 0.26 \\
\hline
\end{tabular}

The elastic modulus of wearing coat in coded values and the corresponding extreme values predicted by the model:

$$
\begin{aligned}
& E\left(x_{1}, x_{2}, x_{3}\right)=3.743-1.177 x_{1}+0.597 x_{3}+ \\
+ & 0.898 x_{1} x_{2}-0.643 x_{2} x_{3}-0.583 x_{1} x_{3}+ \\
& +0.866 x_{1}^{2}+1.6 \cdot x_{3}^{2} \\
\mathrm{E}^{\max } & (-1.215,-1.215,1.215)=12.674 \cdot 10^{2}\{\mathrm{MPa}\}
\end{aligned}
$$

The elastic modulus of the layer beneath:

$$
\begin{aligned}
& E_{\text {layer }}^{\text {lower }}\left(x_{1}, x_{2}, x_{3}\right)=5.449-0.195 x_{1}+0.891 x_{2}+ \\
& +0.944 x_{3}+0.588 x_{1} x_{2}+0.93 x_{2} x_{3}+ \\
& +0.291 x_{1}^{2}-0.25 x_{2}^{2}+0.555 \cdot x_{3}^{2} \text {, } \\
& \text { lower } \\
& E_{\text {layer }}^{\text {satur }} \\
& \text { where } E_{\text {layer }}-\mathrm{E} \text { elastic modulus of the lower saturated layer } \\
& \mathrm{E}_{\text {lower }}^{\max }(1.215,1.215,1.215)=10.562 \cdot 10^{2}\{\mathrm{MPa}\} \text {. }
\end{aligned}
$$

The undisturbed viscosity structure of unsaturated samples:

$\eta\left(\mathrm{x}_{1}, \mathrm{x}_{2}, \mathrm{x}_{3}\right)=1.124+0.168 \mathrm{x}_{1}+0.081 \mathrm{x}_{2}-0.141 \mathrm{x}_{3}-0.025 \mathrm{x}_{1} \mathrm{x}_{2}-$ $0.042 \mathrm{x}_{2} \mathrm{x}_{3}-0.043 \mathrm{x}_{1} \mathrm{x}_{3}-0.078 \mathrm{x}_{1}{ }^{2}-0.355 \mathrm{x}_{2}^{2}-0.25 \mathrm{x}_{3}^{2}$.

$$
\eta^{\max }(1.215,0.093,-0.394)=1.253 \cdot 10^{10}\{\text { Poise }\} \text {. }
$$

Such indices for SMA as strength, elastic modulus and the undisturbed viscosity structure as well as the international roughness index IRI were obtained based on the results of the completed researches (see Fig. 1).

The international roughness index in accordance to the Russian National Standard GOST R 56925-2016 [5]: $\operatorname{IRI}^{\mathrm{max}}=8,0\{\mathrm{~m} / \mathrm{km}\}-$ for V road status; IRI ${ }^{\mathrm{min}}=3,4 \cdot\{\mathrm{m} / \mathrm{km}\}-$ for I road status. The equation of constraints between the IRI index and ground clearance under a leveling beam [6]:

$$
\text { IRI }=1,65+0,08+0,0005 \mathrm{P}^{2},
$$

where $\mathrm{P}$ - number of ground clearance under a leveling beam exceeding $3 \mathrm{~mm}$, in $\%$ of the total number of measurements (the IRI value equal to 2 corresponds to $\mathrm{P}=5 \%$ ).
As reflected by the regression equation the model largest value often falls on the boundary values of the examined place restricted by variable parameter limits. This indicates the need to introduce a special efficiency criterion, the total risk of a weighted sum of factors in the planning model of the experiment and regression models that have allowed finding optimal compositions with high mathematical accuracy. At the same time, the technical risk assessment covers practically the full variation range of changing factors.

If we combine the approach of regression model with the theory of risk, we will get the initial preconditions for calculating the risk at the stage of selecting the composition of asphalt concretes which are presented in paper [3]. The compressive strength is determined from the condition proposed by Professor N.N. Ivanov when replacing the value of compressive strength obtained from the tests results of cores selected from the coating to those which are deduced from the results of mathematical experiment planning:

$$
\mathrm{R}_{\text {compressive strength }} \geq \frac{2 P \cdot K \cdot h}{D \cdot \operatorname{tg} 45^{0}+\frac{\varphi}{2}}
$$

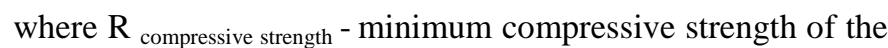
material of the layer beneath which ensures that it will not be destroyed by the car wheel while direct contacting or pressing material fragments of the overlying layer, $\{\mathrm{MPa}\}$ (it is deduced from the regression equation). $\mathrm{P}$ is the greatest specific pressure from the car wheel at the contacting point with the coating (in accordance with Model building codes 4683 , it is assumed $=0.6\{\mathrm{MPa}\}$ for $\mathrm{A}$ group load, it is 0.5 $\{\mathrm{MPa}\}$ for $\mathrm{B}$ group). $\mathrm{K}$ is a coefficient taking into account the influence of horizontal forces and material plasticity of the manufacturable coating (for light road conditions $\mathrm{K}=3 \div 6$, in areas with difficult conditions $\mathrm{K}=6 \div 12$ and with dangerous road ones $K=12 \div 18$. Smaller values are chosen for the average traffic intensity and for more rigid road surface materials. Larger values are chosen for plastic materials and heavy traffic); $\mathrm{h}$ is the thickness of the underlying coating layer, $\mathrm{cm}$; D is the diameter of the tire tread contact (for group A load $=37\{\mathrm{~cm}\}$, for group B load $=32\{\mathrm{~cm}\}) . \varphi$ is the angle of materials internal friction of the underlying zero layer (it is determined by the shear material test). [7]:

The bending tensile test is determined from the condition

$$
\mathrm{R}_{\mathrm{b}} \geq \sigma_{\mathrm{r}},
$$

where $R_{b}$ (bending) is allowed material tensile stress of the tested layer, $\{\mathrm{MPa}\}$ (it can be deduced from the regression equation restricted by the formula):

$$
\mathrm{R}_{\mathrm{b}}=\mathrm{R} \cdot\left(1-\mathrm{t} \cdot v_{\mathrm{R}}\right) \cdot \mathrm{K}_{\mathrm{y}} \cdot \mathrm{K}_{\mathrm{m}},
$$

where $\mathrm{R}$ - average material resistance of the underlying layer of the coating to stretching during bending, $\mathrm{MPa}$ (it is determined by material bending test); $\mathrm{t}$ is the standard variation coefficient $\mathrm{R}$, assumed depending on the design reliability level (according to Table 2); $v_{\mathrm{R}}$ is the coefficient of variability assumed $=0,1 ; \mathrm{K}_{\mathrm{y}}$ is the fatigue ratio depending on the traffic intensity (accepted for asphalt concretes according to the nomogram chart of Fig.8 of Model building codes MBC 46-83). 
TABLE 2. DEPENDENCE OF THE STANDARD VARIATION COEFFICIENT ON THE DESIGN RELIABILITY LEVEL

\begin{tabular}{|l|l|l|l|}
\hline Design reliability level & 0.85 & 0.9 & 0.95 \\
\hline The standard variation coefficient t & 1.06 & 1.32 & 1.71 \\
\hline
\end{tabular}

$\mathrm{K}_{\mathrm{m}}$ is the coefficient of strength reduction from natural factors (assumed for I and II asphalt concrete grade on extrusive rock $\mathrm{Km}=1,0$ and the III-rd $\mathrm{K}_{\mathrm{m}}=0,8$; for mixtures on gravel of sedimentary rocks and gravels of the I-st grade $\mathrm{K}_{\mathrm{m}}=0$,9; for the II-nd and III-rd grades $\mathrm{K}_{\mathrm{m}}=0.7$; for bitumen concrete $K_{\mathrm{m}}=0,7$ ); $\sigma \mathrm{r}$ is the maximum tensile stress, MP, on the load, which is found by the formula:

$$
\sigma_{\mathrm{r}}=\sigma_{\mathrm{r}} \cdot \mathrm{P} \cdot \mathrm{K}_{\mathrm{s}},
$$

where $\sigma_{r}$ is the estimated tensile stress of the bending under a single load in the treated layer of the coating, MP (determined either by the nomogram of the Fig. 3.11 or by the Fig. 3.12 of MBS 46-83); $\mathrm{P}$ is the vertical specific pressure at the point of the contact of the car's tire with a coating, MP (for the group A load is $0.6\{\mathrm{MPa}\}$, for the group B load is $0.5\{\mathrm{MPa}\}) ; K_{s}$ is the coefficient, taking into account the peculiarities of the stressed state (it is assumed to be equal to 0.85 ).

To implement the calculations, taking into account the regression models and the introduction of constraints from formulas $(7,8)$ that limit the risks for a given level of responsibility for the road section, we have developed a program for calculating the risk in the Math Cad software module. At the algorithm input, the program is given the obtained regression dependencies, the formula for the criterion of optimality, for example, the viscosity of an undisturbed structure and elastic modulus:

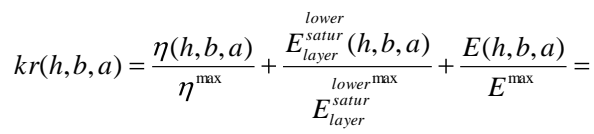

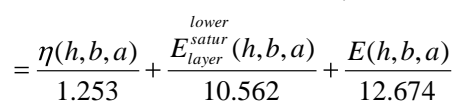

where $\eta(h, b, a)$ and $\eta^{\max }-$ respectively, the regression equation for the viscosity of the undisturbed structure and the maximum value predicted by the model; $\mathrm{E}(\mathrm{h}, \mathrm{b}, \mathrm{a})$ and $\begin{array}{r}\text { lower } \\ E_{\text {layer }}^{\text {satur }}\end{array}$ $(\mathrm{h}, \mathrm{b}, \mathrm{a})$ are the regression equations for the modulus of elasticity of the upper and lower layers of the pavement. Mathematically, the criterion of optimality is similar to the quantitative estimate of the risk of a linear model of the weighted sum of factors in the work [4]. The only difference is that the desired values of the criterion of optimality should be maximum, and the risk is minimal. In order to switch to the risks, it is necessary to turn the numerator and denominator of each term and set the criterion values, let us call it the risk of the weighted sum of factors, to a minimum. Then, we get:

$$
\begin{aligned}
& R=A_{1} \frac{w^{\min }}{w(h, b, a)}+A_{2} \frac{w_{l o n}^{\min }}{w_{l o n}(h, b, a)}+A_{3} \frac{R_{s}(h, b, a)}{R_{s}^{\max }}+ \\
& +A_{4} \frac{E(h, b, a)}{E^{\max }}+A_{5} \frac{I R I_{\min }}{\operatorname{IRI}(P)}
\end{aligned}
$$

where $A_{1}, A_{2} \ldots A_{n}$ - are the coefficients of factors' significance (the importance of the factor is determined by the expert method, depending on the probability); w (h,b,a), w ${ }^{\text {lon }}(h, b, a)$ the regression equation for water saturation of asphalt concrete and long water saturation of asphalt concrete; $R_{s}(h, b, a)-$ the regression equation for the compressive strength of asphalt concrete; IRI (P)- the regression equation for the international roughness index (refer with Eq. 2).

To obtain a value from $0 \%$ to $100 \%$, we normalize the total risk by the formula:

$$
\mathrm{Y}=100 \% \cdot\left(\mathrm{R}-\mathrm{R}_{\min }\right) /\left(\mathrm{R}_{\max }-\mathrm{R}_{\min }\right) \text {, }
$$

\begin{tabular}{|c|c|c|c|c|c|c|c|c|c|}
\hline \multirow{15}{*}{$\operatorname{upor}(\mathrm{F})=$} & & 0 & 1 & 2 & 3 & 4 & 5 & 6 & 7 \\
\hline & 0 & 0.062 & 1.215 & -1.215 & -1.215 & 2.349 & 2.767 & 7.604 & 6.577 \\
\hline & 1 & 0.062 & 1.215 & \begin{tabular}{|c|}
-1.215 \\
\end{tabular} & -1.015 & 2.511 & 2.808 & 7.308 & 6.292 \\
\hline & 2 & 0.062 & 1.215 & \begin{tabular}{|c|}
-1.215 \\
\end{tabular} & -0.815 & 2.648 & 2.835 & 7.139 & 6.052 \\
\hline & 3 & 0.062 & 1.215 & -1.215 & -0.615 & 2.763 & 2.847 & 7.099 & 5.856 \\
\hline & 4 & 0.062 & 1.215 & \begin{tabular}{|c|}
-1.215 \\
\end{tabular} & -0.415 & 2.853 & 2.845 & 7.187 & 5.705 \\
\hline & 5 & 0.063 & 1.215 & \begin{tabular}{|c|}
-1.215 \\
\end{tabular} & \begin{tabular}{|c|}
-0.215 \\
\end{tabular} & 2.92 & 2.828 & 7.402 & 5.598 \\
\hline & 6 & 0.063 & 1.215 & \begin{tabular}{|c|}
-1.215 \\
\end{tabular} & $\mid-0.015$ & 2.964 & 2.797 & 7.746 & 5.535 \\
\hline & 7 & 0.064 & 1.215 & \begin{tabular}{|c|}
-1.215 \\
\end{tabular} & 0.185 & 2.984 & 2.751 & 8.218 & 5.516 \\
\hline & 8 & 0.064 & 1.215 & \begin{tabular}{|c|}
-1.215 \\
\end{tabular} & 0.385 & 2.98 & 2.691 & 8.818 & 5.543 \\
\hline & 9 & 0.065 & 1.215 & \begin{tabular}{|c|}
-1.215 \\
\end{tabular} & 0.585 & 2.952 & 2.616 & 9.545 & 5.613 \\
\hline & 10 & 0.066 & 1.215 & \begin{tabular}{|c|}
-1.215 \\
\end{tabular} & 0.785 & 2.901 & 2.527 & 10.401 & 5.728 \\
\hline & 11 & 0.067 & 1.215 & \begin{tabular}{|l|}
-1.215 \\
\end{tabular} & 0.985 & 2.827 & 2.424 & 11.385 & 5.887 \\
\hline & 12 & 0.068 & 1.215 & \begin{tabular}{|c|}
-1.215 \\
\end{tabular} & 1.185 & 2.729 & 2.306 & 12.496 & 6.091 \\
\hline & 13 & 0.068 & 1.215 & \begin{tabular}{|l|}
-1.215 \\
\end{tabular} & 1.215 & 2.712 & 2.287 & 12.674 & \\
\hline
\end{tabular}

where $\mathrm{R}_{\min }$ - minimum possible risk assessment (refer with: Fig.2); $\mathrm{R}_{\max }$ - the maximum risk assessment from Fig. 2.

Fig. 2. The results of calculating the criterion in the MathCad program: Column No 0 - Risc, No $1 \ldots 3$ - factors h,b,a; No $4 \ldots 7$ - parameters p,pn,e,en

Next, the program calculates the maximum and minimum values of the optimality criterion and the corresponding combinations of parameters (refer with Fig. 2). So, the minimum risk corresponds to the values $\mathrm{x}_{1}=0.585$, bitumen $\mathrm{x}_{2}=-1.215, \mathrm{x}_{3}=-0.615$. The value of the normalized risk is normalized by the total risk value by the Eq.11: $Y=100 \%$. $(0,07-0,05) /(0,085-0,05)=57 \%$ - the value corresponding to the requirements for the modulus of elasticity $\left(\mathrm{E}=10,4 \quad 10^{-2}\right.$ $\{\mathrm{MPa}\})$, the required strength $\mathrm{P}=2.9\{\mathrm{MPa}\}$ and the minimum IRI =2).

It is known that the technical regulations developed in accordance with Federal Law №384-FL should regulate the acceptable risks of causing harm, establish minimum necessary product requirements that ensure various types of road safety. At the same time, the issue of designing asphaltconcrete, and the selection of asphalt-concrete components at the design stage, taking into account the possible admissible risk and level of responsibility under Federal Law No. 384-FL remain undeveloped. The magnitude of the total risk from all undesirable events on road objects is calculated taking into account the synergistic effect V.V. Stolyarov, when considering the special case of the presence on the site of two causes that give rise to risky situations, suggested the following formula for determining the total risk [8]:

$$
r_{1,2}=r_{1}\left(1-P_{1}\right)+r_{2}\left(1-P_{2}\right)
$$

where $r_{l}$ and $r_{2}$ are the risk magnitude of each cause; $P_{1}-$ the possible probability of the change $r_{l}$ when exposed to $r_{2}$ (a negative impact due to the cause of $\left.r_{2}\right) ; P_{2}$ is the possible 
probability of a change in $r_{2}$ when exposed to $r_{l}$ (a negative effect due to the cause of $r_{l}$ ).

As a result of mathematical transformations, we get a partial equation of the total risk [8]:

$$
r_{1,2}=r_{1}+r_{2}-r_{1} r_{2}
$$

If there are some causes on the road section $n$ that determine the risk values $r_{1}, r_{2}, \ldots r_{n}$ V.V. Stolyarov proposed using Eq. 13 successively $n-1$ times. Then, we calculate the total risk for any two-risk values (for example, $r_{1}$ and $r_{2}$ ). The subsequent calculations are made with arbitrary indexation of risk values. Any sequence of addition of risk leads to the total risk, which remains less than or equal to one if there is an unlimited number of values $r_{i}\left(0 \leq r_{i} \leq 1\right)$.

The introduction of coefficients before the corresponding quality indices of the developed composition of asphalt concrete allows one to take into account the increase in the safety factor (elasticity modulus, roughness) because of the necessity to consider the risks of failure to achieve the required parameters, respectively: the strength of the upper layer in the case of high-speed traffic of predominantly passenger cars with shock load on the coating, the risk of unforeseen decline strength of the underlying layer, the risk of an accident due to poor visibility conditions or the increasing number of defects on the surface, the risk of an accident on the dangerous areas of intense braking. They are most often a consequence of poor quality of the road surface due to the insufficient strength and durability of the asphalt concrete used in this coating. By the way, the World Road Association indicates that the friction coefficient decreasing on the road below 0.45 will increase the risk of accident by 20 times; when it goes below 0.30 the risk is by 300 times higher [12].

In conclusion, we would like to note that the studies of slag asphalt concrete and crushed stone-mastic asphalt concretes on the basis of slag aggregates continue. A tripartite agreement is being negotiated between NLMK PJSC, The State company «Russian highways» and MADI for in-depth studies of the properties of these asphalt concretes on modern test equipment by the authors' team, indicated in the publication [2]. Additional publications with research results are planned after the completion of these works.

Thus research results presented in this paper have proved high physical and mechanical properties of SMA on blastfurnace slag aggregates which have almost complete crystallization and provide increased strength and abrasion resistance to asphalt concretes due to high adhesion to binders.

\section{SUMMARY}

1. The research of technical risk carried out in this work during the planning of the experiment made it possible to quantify the risks in regression models with high accuracy.

2. The compensation of accumulated risks requires an increase in the margin for strength, smoothness or roughness of the road surface, taking into account the level of responsibility for the linear structure under Federal Law No. 384-FL.
3. By combining the theory of risks of V.V. Stolyarov and using predictive models of regression equations at the planning stages of the experiment, one can predict the dependence of the expected level of reliability of the road from the planned factors at the stage of selecting the composition.

4. Regression equations make it possible to obtain the maximum possible values of the variable parameters for a given model, and the use of the theory of risks makes it possible to take into account the advisability of increasing reliability of the structure during the operation stage.

5. Combining the approaches of the mathematical apparatus of the theory of reliability and the theory of risks, one can obtain economic justified values of the efficiency coefficient and thereby compensate for the risks, as required by the current system of technical regulation. The accumulation of statistical data on this model will allow one in the future to lay risk rationing in the requirements of technical regulations.

\section{References}

[1] B.A. Bondarev, Yu.V. Shtephan "Studies of SMA on blast-furnace slag aggregates in laboratory and field conditions", Engineering systems and facilities, vol.17, pp.13-20, 2014.

[2] Yu.V. Shtefan, Yu.E. Vasiliev, V.V.Talalay, "Technical regulation and quality control of road construction materials and performed repairs in urban conditions", Newspaper Russian Road Worker, vol. 24, http://www.aspor.ru/publishers/?page=pages_1535, June 8, 2017.

[3] D.A. Strizhevsky, L.V. Yankovsky, A.V. Kochetkov, "Study of improving road safety by taking into account the IRI index and the complex indicator of the transport and operational status", Technical regulations in transport construction, vol. 3, pp. 7-11, 2014.

[4] V.A. Zorin "Risk management at designing, manufacture and operation of road-construction machines", Interstroimech, NRU MSUCE Inc.: Moscow, 2nd ed., pp. 4 - 6, Oktober 2016 [Proceedings of the XXth ISTC, p. 257, 2016].

[5] GOST R 56925-2016 Automobile roads and airfields. Unevenness measurement methods for base courses and pavements.

[6] K.V. Mogilniy, N.A. Lushnikov, O.A. Krasikov, "International roughness index and its usage in the countries of the customs union", Roads and bridges, vol. 1. (29), pp. 92-112, 2013.

[7] A.V. Kochetkov, L.V. Yankovsky Yu.A. Trofimenko, "Developing technologies of the application of thin wear layers and rough road surface treatments", Naukovedenie, vol. 23, pp.1-20, August 2014.

[8] V.V. Stolyarov, Engineering of highways taking into account the risk theory, SSTU Sarat. state. tech. un., Saratov, Russia, 1994. (Part 1).

[9] O.F. Shakhov, Sh.N. Valiev, A.V. Kochetkov, S.V. Karpeev, "Methodological bases of an assessment of technical risks in quality management of road economy", Naukovedenie, vol. 7, pp. 1-17, 2016.

[10] S.P. Arzhanukhina, Zh.N. Kadyrov, A.V. Kochetkov, I.G. Shashkov, V.V. Ermolayeva, Method for determining the coefficient of adhesion of the automobile wheel with the road", Naukovodenie, vol. 3, http://naukovedenie.ru/PDF/76TVN315.pdf, pp. 1-10, 2015.

[11] S.V. Karpeev, Improving road safety by upgrading the methods of applying and normalizing the lighting and operational indicators of vertical marking. Russia, Saratov, Diss. Candidate Thesis in Engineering Science 05.22.10, 2011.

[12] J. Čelko, M. Kováč, P. Kotek, "Analysis of the Pavement Surface Texture by 3D Scanner", Transportation Research Procedia, vol.3, pp. 2994-3003, 2016. 